\title{
Hippocratic Bodily "Channels" and Oriental Parallels
}

\author{
E M CRAIK*
}

\section{Introduction}

The argument of this paper is based primarily on a close reading of several Hippocratic texts ${ }^{1}$ parallels with Chinese traditional medicine are adduced. Study of Greek medicine is usually situated in the context of western medical history. However, it is evident that the vascular anatomy envisaged in the Hippocratic Corpus is not at all coincident with our known post-Harveian model; it here becomes apparent that it is coincident rather with Chinese patterns. The supposed working and actual treatment of the body are fundamental concerns of doctors in any society, but different suppositions have been made, and different practices followed, in different ages and different places. When the evidence from Greek and Chinese traditions is pared down to parallel analysis under the broad heads of physiology (nature of the body), pathology (nature of disease) and surgery (nature of treatment), remarkable common essentials and shared anatomical presuppositions are seen to emerge. Parallel analysis of a specialist field, ophthalmology, reveals common elements also.

There are obvious limitations and difficulties in essaying an approach which is neither clearly synchronic nor firmly diachronic. Once similarities between two modes of thought have been isolated, quid sequitur? Similarities in practice can readily be explained by common human physiology: doctors of different societies at different times

\section{(C) E M Craik 2009}

*Professor E M Craik, School of Classics, University of St Andrews, St Andrews KY16 9AL, UK; and Classics, School of Historical Studies, University of Newcastle upon Tyne, Newcastle upon Tyne NE1 7RU, UK.

I am very grateful to three anonymous referees of Medical History for extremely helpful and constructive comments on this paper; also to the Acting Editor, Professor Vivian Nutton, for pertinent overarching remarks and guidance. As a result of their comments, the paper has been much improved and somewhat extended. A previous version was presented at the first European meeting of the Society for Ancient Medicine, organized by Professor Robert Arnott at the University of Birmingham in June 2004. Proceedings of that meeting were projected and advertised, but never published. A second article (Craik, 'Myelos: matters of life and death', Acta Classica Supplement II, Asklepios: studies on ancient medicine, ed. L Cilliers, Bloemfontein, 2008, pp. 64-73) referring to one in these phantom Proceedings, has now appeared before this revised version of that putative first.
I was first prompted to consider comparisons between the medical theory and practice of east and west when lecturing on Hippocrates at Kyoto University (as Professor of Classics from 1997 to 2002): students introduced me at an early point to the flourishing trade of KANPO shops, and later to colleagues practising acupuncture and moxibustion at the Meiji University, Kyoto. I was stimulated to develop these ideas by a meeting and discussion with Professor Shigehisa Kuriyama, and much aided by consultation with Dr Vivienne Lo. It is a pleasure to acknowledge their generous advice on early Chinese medical history.

\footnotetext{
${ }^{1}$ References are given by chapter numbers, with the addition in square brackets of volume and page numbers in E Littré, Oeuvres complètes d'Hippocrate, 10 vols, Paris, J-B Baillière, 1839-61, the standard Greek text with French translation of the complete corpus. The most accessible English translation-available for most, though not all, Hippocratic works - is in the eight volumes of the Loeb Classical Library (by different scholars), Cambridge, MA, and London, Harvard University Press, 1923-95.
} 


\section{E M Craik}

might treat similar afflictions in a similar way because they separately have discovered an effective treatment on an empirical pragmatic basis. Similarities in theory are less readily explicable. In general, there are two ways to account for these: firstly, contacts and interactions between peoples, with consequent influence, whether one-way in one of two directions, or two-way in both; or secondly, independent appearance of similar modes of thought. Some tentative conclusions - and questions - are put forward in the final section. The possibility that remote contacts may have left vestigial traces in the earliest evidence for both Greek and Chinese medical traditions is aired. And finally, it is suggested that western medicine may be less firmly rooted in the Greek past than historians and practitioners alike tend to believe.

The nature of the evidence, complex on both sides, requires a brief preliminary discussion. The Hippocratic Corpus, as we know it, comprises some sixty to seventy treatises. There is a growing scholarly consensus that the quest, initiated in antiquity and continued until the middle of the twentieth century, for "genuine" Hippocratic works among them is futile: they are so disparate in expression and content that, at best, broad groupings of related works can be established. ${ }^{2}$ It is now recognized too that other medical writing from the classical period (fifth and fourth centuries BC), not generally regarded as "Hippocratic", may once have had comparable status. A collection of evidence for the survival and usage of the Corpus in antiquity exposes the fragility of our post-publication and post-renaissance Hippocratic construct. ${ }^{3}$ It is unsurprising that, with regard to the particular questions addressed here, the views presented in the Corpus, itself heterogeneous, are not entirely homogeneous.

For Chinese medicine there is no documentary evidence, and very little evidence of any kind, before early second century $\mathrm{BC}$. That is not to say that medicine begins in this period, merely that evidence before the Han period cannot be safely reconstructed: in view of the disturbed political conditions, this is unsurprising. The first published translation of the earlier part of the Nei Ching (Neijing) remains useful. Its content is the basis of exposition in many secondary works on Chinese medicine. ${ }^{4}$ Although the text of this monumental Classic of internal medicine is difficult and uncertain and its date disputed, the general content, in many respects already clear, can be supplemented and reconstructed from later recensions and interpretations, such as that of the Ming period; also by medical texts found in tombs of the second century BC (the Mawangdui tombs).

There are evident hazards in comparing the amorphous Hippocratic material with the still more amorphous material from China. ${ }^{5}$ Nevertheless, despite variations in the Greek

\footnotetext{
${ }^{2}$ See the assumptions made in the title and throughout by Francis Adams (transl.), The genuine works of Hippocrates, 2 vols, London, Sydenham Society, 1849, and contrast the stance of Vivian Nutton, Ancient medicine, London, Routledge, 2004, pp. 53-71.

${ }^{3}$ Anargyros Anastassiou and Dieter Irmer (eds), Testimonien zum Corpus Hippocraticum, Teil I: Nachleben der hippokratischen Schriften, Göttingen, Vandenhoeck \& Ruprecht, 2006.

${ }^{4}$ Ilza Veith, Huang Ti Nei Ching Su Wen: the Yellow Emperor's classic of internal medicine,
}

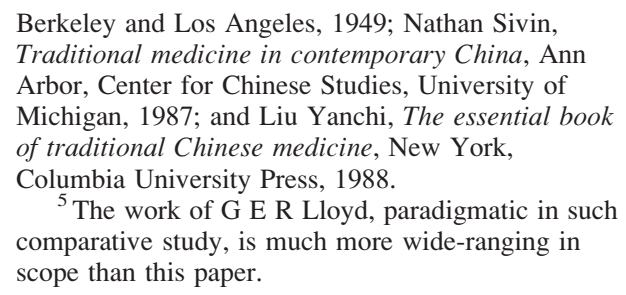
Traditional medicine in contemporary China, Ann Arbor, Center for Chinese Studies, University of Michigan, 1987; and Liu Yanchi, The essential book of traditional Chinese medicine, New York, Columbia University Press, 1988.

${ }^{5}$ The work of G E R Lloyd, paradigmatic in such comparative study, is much more wide-ranging in scope than this paper. 


\section{Hippocratic Bodily “Channels" and Oriental Parallels}

evidence, certain common elements in theory and practice can be isolated; and despite the paucity of early evidence from China, an abundance of later evidence compensates.

\section{Physiology: Nature of the Body}

In the Hippocratic Corpus, the body is viewed as important bits (organs, viscera such as lungs, liver, kidneys) and orifices (including eyes, ears, genitals) linked by hollow tubes, ducts or channels of which the most important are the phlebes (especially, but not exclusively, blood vessels: veins and arteries, not distinguished), and solid threads for which the general term is neura (ligaments, nerves, etc.). The Hippocratic writers were aware that such explanations did not meet the complexity of the body and allowed for passages intermediate between phlebes and neura (variously described, e.g. as "hollow neura"); also, in addition to the regular channels, for irregular ones (given various names, such as poroi) which might "open up" to convey an excess of fluids. These refinements do not concern us here. What does concern us is the way in which the main vascular system was envisaged, especially with regard to vessels in the head and neck (route to the lower body); also views of the contents of the vessels in a healthy and unhealthy state.

It must be stressed that the Hippocratic authors are not aiming to present abstract anatomical surveys (though the composite works On bones and On anatomy come closest to this); but rather to offer practical adjuncts to physiological understanding (as, with regard to flux theory, in Places in man) or aids in therapeutic intervention (as, with regard to phlebotomy, in Nature of man). The general treatise On anatomy deals only incidentally with the vessels, viewed as bodily links. The most detailed account is in the treatise On bones. In addition to these Hippocratic versions of the course of the vessels, there are accounts written for non-medical purposes in the fragmentary remains of the pre-Socratic philosopher Diogenes of Apollonia ( $f l$. early in the second half of the fifth century BC) and in Plato's Timaeus. ${ }^{6}$

It is appropriate to begin with the vascular anatomy tacitly postulated by Homer in the Iliad, our oldest extant Greek text. Homer uses the word phleps "vessel" only once: a hero dies when the single phleps said to travel right up the back and through the neck is severed. "Antilochos, watching Thoon as he turned around, sped in and struck him down; and he slashed away the entire vessel which runs all the way up the back and passes through the neck." "Aristotle in History of animals cites the passage, regarding phleps as a reference to the vena cava, ${ }^{8}$ and this view has been followed by some modern scholars. Others however are sceptical, on the grounds that the vessel described seems superficial, that it is reached by a spear from behind, and that the reference is to a duct running up the neck, between head and trunk. For these reasons, the jugular vein

\footnotetext{
${ }^{6}$ On Diogenes of Apollonia, see G E R Lloyd, 'Diogenes of Apollonia: master of ducts', in Maria Michaela Sassi (ed.), La costruzione del discorso filosofico nell' età dei presocratici, Pisa, Edizioni della Normale, 2006, especially at p. 254, on the general disregard by early Greek thinkers of the
}

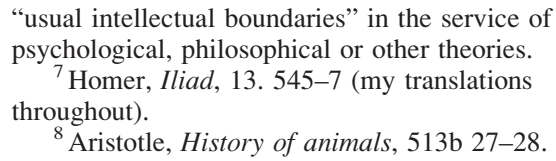
psychological, philosophical or other theories.

${ }^{7}$ Homer, Iliad, 13. 545-7 (my translations throughout)

${ }^{8}$ Aristotle, History of animals, 513b 27-28. 


\section{E M Craik}

or the carotid artery have been canvassed. Others again regard the whole description as fantastic, with no correspondence to reality. ${ }^{9}$

Homer's medical, and especially anatomical, knowledge was celebrated already in antiquity: Galen frequently cites epic verse in his Hippocratic commentaries, and may himself have written a work on the subject of "Medicine in Homer". ${ }^{10}$ If no blood vessel corresponding exactly to the course described can be identified, the lapse in Homer's anatomical precision seems surprising. However, we may note that Homer in postulating the presence of a phleps says nothing of blood, and that a duct does exist, following the course described: that carrying cerebro-spinal fluid. ${ }^{11}$ A second passage is relevant, and makes the Homeric conception clear: a hero is beheaded and myelos "marrow" is said to spurt out. "Achilles struck the neck with his sword and tossed the head, helmet and all, to a distance; the myelos 'marrow' spurted from the vertebrae and the man sprawled, laid low." 12 This description is generally dismissed without much discussion. ${ }^{13}$

Just as phleps "vessel" is a sole occurrence in the first passage, ${ }^{14}$ so the term sphondylion or sphondylos "vertebra" is a sole occurrence in the second. ${ }^{15}$ The diminutive sphondylion is explained as a diminutive "in form only" or as a term introduced for the sake of the metre, to avoid a cretic; ${ }^{16}$ however, the diminutive fits the sense, as the cervical vertebrae are relatively small. Further anatomical terminology associated with the head and neck is known to Homer, though rare in the epics. A related single occurrence is brechmos the equivalent of the later bregma ("vertex", or anterior fontanelles) in a description of a hero's headlong fall. "Antilochos sped in and struck with his spear ... and he toppled from his chariot ... on brechmos and shoulders." ${ }^{\prime 7}$ The root sense brecho surely conveys an area where moisture was believed to collect rather than (as Liddell and Scott in the standard Lexicon) "because this part of the bone is longest in hardening". The etymology then is associated with medical theory (on which, see further below) and awareness of the theory seems to be implicit in our earliest text. For correct translation of Homeric terminology it is necessary to forget our preconceptions based on all the familiar words derived from the root phlebo- referring to the veins. As phleps is simply a "duct" or a "channel" the translation "vein" or "blood vessel" is inappropriate and anachronistic. The translation "marrow" is misleading also, as, although myelos (Ionic myalos) can refer to bone marrow, it refers much more commonly to cerebral or spinal fluid;

\footnotetext{
${ }^{9}$ See Charles V Daremberg, La médecine dans Homère, Paris, Didier, 1865 (jugular); Otto Körner, Die aerztlichen Kenntnisse in Ilias und Odyssee, Munich, Bergmann, 1929 (aorta with carotid, or vena cava with jugular); Wolf-Hartmut H Friedrich Verwundung und Tod in der Ilias, Göttingen, Vandenhoeck \& Ruprecht, 1956 ("Scheinrealismus"); Fridolf Kudlien, 'Zum Thema "Homer und die Medizin"', Rheinisches Museum, 1965, 108: 293-9 (persuaded by Aristotle); see also A H M Kerkhoff, 'Ein anatomicum bei Homer', Rheinisches Museum, 1981, 124: 193-5.

${ }^{10}$ See Kudlien, op. cit., note 9 above, pp. 295-9.

${ }^{11}$ Thus Richard Janko, The Iliad: a commentary, vol. 4, bks 13-16, Cambridge University Press, 1992, ad loc. correctly annotates "... surely the spinal chord ....".
}

\footnotetext{
${ }^{12}$ Homer, Iliad, 20. 481-3.

${ }^{13}$ Thus Mark W Edwards, The Iliad: a commentary, vol. 5, bks 17-20, Cambridge University Press, 1991, ad loc. cursorily annotates "anatomically impossible".

${ }^{14}$ Homer, Iliad, 13. 546.

${ }^{15}$ Homer, Iliad, 20. 483.

${ }^{16}$ Henry G Liddell and Robert Scott, $A$ Greek-English lexicon, Oxford, Clarendon Press, many editions, s.v.; Edwards, op. cit., note 13 above, ad loc.

${ }^{17}$ Homer, Iliad, 5. 584-6. G S Kirk, The Iliad: $a$ commentary, vol. 2, books 5-8, Cambridge University Press, 1990, ad loc. regards this encounter as a "pure flight of fancy".
} 


\section{Hippocratic Bodily “Channels” and Oriental Parallels}

this inconsistent nomenclature was castigated by the author of the Hippocratic work $O n$ flesh. $^{18}$

The treatise On bones brings together various views of the vascular system with similarities and inconsistencies alike apparent. Although these accounts are confused and fanciful in details, a salient common supposition is that the vessels originate in the head. That different vocabulary (two words for "neck" and two for "back") is employed in different sections to express the routes of phlebes reveals the diverse sources for these beliefs. Different parts of On bones can be traced to different sources and different authors. On bones 1-7 probably and On bones 11-18 certainly derive from a work described by Galen in his work on Hippocratic glosses as 'Appendix to Mochlicon'; ${ }^{19}$ On bones 8 is attributed by Aristotle to the little-known Syennesis of Cyprus; ${ }^{20}$ On bones 9, attributed by Aristotle to Polybos son-in-law of Hippocrates, replicates Nature of man $11,{ }^{21}$ and On bones 10 replicates Epidemics 2. 4. 1. ${ }^{22}$ In most accounts, as in that attributed to Polybos, it is supposed that the vessels go in pairs. The supposition of such pairing may be based in part on observation of visible conjunctions of veins and arteries, but is more probably conditioned by assumptions of bodily symmetry and by the Greek tendency to favour duality and contrast in modes of thought. ${ }^{23}$

Exceptionally, in On bones 11-18 there is one central vessel. ${ }^{24}$ This vessel is described by the unexpected adjective archaie as "the ancient vessel" or perhaps "the fundamental/original vessel", a term occurring only here in the Corpus. Critics have mistranslated "main" vessel; or emended archaie "ancient" to pacheie "thick", but neither expedient is helpful. ${ }^{25}$ The tortuous course of this single vessel running all round the body, associated with both respiration and reproduction, in places "white and sinewy", with many interconnecting small vessels, is described: it passes behind the midriff (diaphragm), and through the neck and throat; it is "rooted" in the genitals and "intertwined like ivy" with the "marrow"; above all, its course is closely associated with that of the akantha "spine" (eleven times repeated in the description). We may note that the extended description in On bones of the "ancient vessel" is preceded by a brief account of its running around the entire head, where a complex network of channels leads to the brain; ${ }^{26}$ also that in Places in man, a single vessel is believed to run from crown of head via forehead to bridge of nose. ${ }^{27}$ Little in the postulated routes corresponds with the realities of observation or of anatomy. However, we see that Homer's belief that a vessel

\footnotetext{
${ }^{18}$ Carn. 4 [Littré, 8. 588]. For a fuller discussion of the anatomy of the spine, see E M Craik, 'Myelos: matters of life and death', Acta Classica Supplement II, Asklepios: studies on ancient medicine, ed. L. Cilliers, Blomfontein, 2008, pp. 64-73.

${ }^{19}$ Oss. 1-7 [Littré, 9. 168-74]; Oss. 11-18 [Littré, 9. 182-94]; Galen, Opera omnia, ed. with Latin transl. C G Kühn, 20 vols, Leipzig, C Cnobloch, 1821-30, Linguarum seu dictionum exoletarum Hippocratis explicatio, 19. 128.

${ }^{20}$ Oss. 8 [Littré, 9. 174]; Aristotle, History of animals, 511b 24-30.

${ }^{21}$ Oss. 9 [Littré, 9. 174-8]; Nat. Hom. 11 [Littré, 6. 58].
}

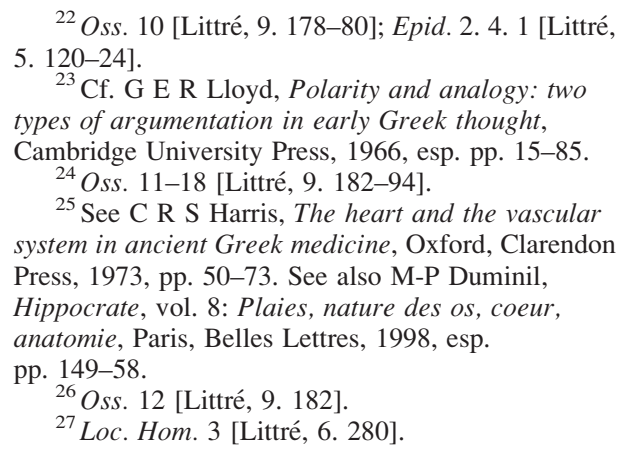




\section{E M Craik}

carrying myelos travelled through the neck has a Hippocratic analogue in the "ancient vessel" of On bones.

Chinese medicine resembles Hippocratic theory in that anatomical structures and orifices (perhaps better described as systems and processes) are seen in terms of the channels which link them to one another and to other areas of the body. Greek phlebes and Chinese mo are significant in physiology (normal-carrying blood and pneuma or qi) and pathology (abnormal-carrying noxious matter, inducing disease). Their supposed paths do not exactly coincide, but several are broadly similar (and more similar to each other than either is to the observed paths of arteries and veins). In particular, the route of the Chinese $d u$ channel ("governor vessel") from spine to back of head carrying life force is similar to that of the Greek vessel carrying vital myelos. And the vessel centrally placed in the forehead in some Greek accounts is similar to the anterior continuation of the Chinese $d u$ channel. Furthermore, the parallel pairs of vessels symmetrically placed on either side of the $d u$ channel correspond with the parallel pairs of vessels postulated in many Greek accounts.

Miniature models illustrating the channels and acupuncture points can be seen in modern pharmacies purveying traditional Chinese cures. Such silent testimony has a long history. Roughly contemporary with medical texts found in tombs dated to 168 BC (the Mawangdui tombs) comes a black lacquered figurine on which six lines or channels are mapped out in red. ${ }^{28}$ The purpose of the figurine and the nature of the channels is opaque, and the relation of the channels to those described in contemporary and later texts (themselves not fully consistent) is imprecise and indeterminate: there is a broad overall similarity but also some variation in detail. On the figurine, the lines run more or less parallel along the length of the body. One line begins between the buttocks and follows the spine to the head: this is analogous to the later $d u$ channel; also to the Homeric phleps and to the archaie phleps of On bones. There are roughly parallel lines on either side: these are analogous to the later pattern of channels; also to the system presented in On bones $9=$ Nature of man $11 .^{29}$

\section{Pathology: Nature of Disease}

Disease is, in Hippocratic terms, regularly associated with peccant matter, noxious stuff, often described simply as "moisture". Whereas in health the vessels carry "good" fluids nourishing the body (primarily, but not only, blood), in illness these fluids are adulterated or unbalanced. Phlegm (especially) and bile are the fluids most regularly implicated in this process, but different accounts are given of their nature and importance. The formal schema of the four humours-phlegm, bile, black bile and bloodsporadic in the Corpus develops fully only later. ${ }^{30}$ Typically, it is supposed by Hippocratic writers that unwanted or excessive moisture gathers in the head, then disperses in flux to some bodily part-eyes, ears, chest etc.—which becomes affected by disease.

\footnotetext{
${ }^{28}$ See He Zhiguo and Vivienne Lo, 'The channels: a preliminary examination of a lacquered figurine from the Western Han period', Early China, 1996, 21: 81-23; Vivienne Lo, 'Spirits of stone: technical considerations in the treatment
}

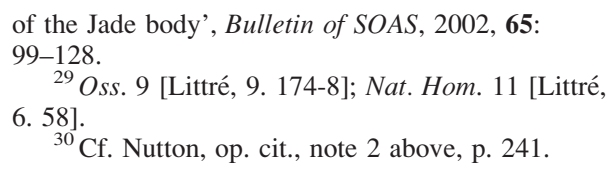




\section{Hippocratic Bodily “Channels” and Oriental Parallels}

There is a particular danger if matter should dry up and become stuck in the bodily ducts or if it cannot be arrested in its progress from the head to other parts of the body. This danger is evident in for example Places in man and Internal affections. ${ }^{31}$

A distinction can be seen between noxious stuff localized in and flowing from the scalp above the skull (hereafter, flux A) and noxious stuff localized in and flowing from the brain below the skull (hereafter, flux B): whereas the former was viewed as common and readily treated, the latter was thought serious and intractable. In discussion of eye troubles in Places in man noxious stuff from the scalp above the skull (flux A) was regularly addressed by treating the flesh of the bregma "vertex" or the vessels of the temples, while noxious stuff from the brain below the skull (flux B) was dangerously inaccessible in its course from brain to eye. ${ }^{32}$ Celsus and Galen, despite huge practical advances not only in ocular anatomy and physiology but also in surgical techniques, continued to subscribe to such theoretical notions. ${ }^{33}$ They exemplify the general medical truth that theory tends to be conservative, while therapy is more innovative.

Diseases presenting at various points in the body were thought to be particularly difficult to treat when the causal flux was associated with the conduit of the myelos "marrow", rather than with other routes in or from the head via phlebes "channels" (to ears or nose), via trachea (to chest) or via oesophagus (to belly). Diseases where the "marrow" was implicated were commonly associated with excess of sexual activity: semen and spinal fluid were allied in early Greek thought. Thus, a deep pathway or pathways from head to lower body, via the myelos, was invoked to explain various intractable conditions. Conditions associated with deep flux from the brain, involving myelos, were more serious than conditions associated with shallow flux from the top of the head, involving other fluids such as phlegma. In Glands as well as in Places in man, the "marrow" carries noxious flux to the back and the hips. In Coan prognoses, a list of diseases not found before puberty (significantly: sexual maturity is involved) includes "flux in the back". ${ }^{34}$ In Internal affections, two types of phthisis "wasting disease" are related to abnormal functioning of the "marrow": in one, the "marrow" becomes filled with blood (or the hollow vessels filled with bile and phlegm); in the other, the "marrow" becomes dry, with blockage in the "small vessels" from the brain. ${ }^{35}$ The route through the neck is often left vague and does not correspond with that of the blood-carrying phlebes: thus, in Places in man cautery between the vessels in the neck is prescribed to stop downward flow. ${ }^{36}$

As we have seen, the archaie phleps "ancient vessel" tends to be disregarded by commentators because it does not correspond with Harvey's vascular realities. It does however correspond with the $d u$ channel of Chinese medical theory. This channel has been highly significant in asceticism and self-cultivation thought. Ideas, especially Daoist ideas, about the desirability of sexual abstinence, and Hippocratic theories about the consequences of over-indulgence in sex are centred on belief in a similarly located bodily duct, which is authenticated in the earliest evidence for both traditions.

${ }^{31}$ Loc. Hom. 2 and 3 [Littré, 6. 280-82]; Int. 13 [Littré, 7. 200].

${ }^{32}$ Loc. Hom. 13 [Littré, 6. 298-302].

${ }^{33}$ Celsus 7. 7. 15; Galen, op. cit., note 19 above, De methodo medendi, 10. 937-42.
${ }^{34}$ Coac. 5. 502 [Littré, 5. 700].

${ }^{35}$ Int. 12, 13 [Littré, 7. 198-200].

${ }^{36}$ Loc. Hom. 21 [Littré, 6. 312-4]. 


\section{E M Craik}

\section{Surgery: Nature of Treatment}

A famous Hippocratic aphorism asserts: "Those diseases that drugs do not cure, the knife cures; those that the knife does not cure, fire cures; those that fire does not cure must be considered incurable." ${ }^{37}$ The drugs most commonly utilized by Hippocratic physicians were purgatives: emetics, laxatives and nasal insertions, the common aim being to eliminate noxious matter, by diverting it to a bodily orifice or, if necessary, to an opening created for the purpose. Cautery and cutting fulfilled broadly similar functions, the aim being to reduce unwanted bodily moisture or to eliminate fleshy tissue. It seems that in the classical period individual practitioners or corporate groups favoured the use of one or the other method. Later, cutting prevailed: Galen made extensive use of phlebotomy but rarely mentions cautery, though he does prescribe it for "streaming eyes". 38 Cautery might be practised almost anywhere in the body (back, chest, neck, head), and applied to fleshy as well as to venous areas, but cautery of the vessels in the head was especially common. The dangers of the procedure were recognized by practitioners and precautions were commonly advised. Other expedients in head surgery are scarification of the scalp at the bregma "vertex" and trephination of the skull. These procedures were prevalent throughout the known world, with considerable local variation according to Celsus, writing in the first century AD. ${ }^{39}$

The translation "cauterize" of the Greek verb kaiein, literally "burn", may be somewhat misleading: the inherent sense "burn" does not necessarily or always involve extreme heat, far less branding and scarring. The sense may be simply "apply heat, using a cauterizing instrument" and the action merely the application of a gentle, soothing warmth, as at times in modern oriental moxibustion. Cautery may be dry (a less invasive treatment) or wet. In dry cautery, the instrument is used simply to apply gentle warmth over or alongside the blood vessels, with a view to changing the consistency or the movement of their contents. In wet cautery, the instrument is placed across them, apparently with the intent of actually breaking the wall of the vessel (hopefully vein, not artery) or even severing it. In both wet and dry procedures, sponges are used to mitigate the pain, to control the severity of the heat, or to mop up blood. (Similarly, in dry cupping, the cupping instrument is applied to the surface of the skin and left there, with the aim of drawing out noxious stuff from the unbroken skin by suction; in wet cupping the skin is broken or scarified in order to remove blood or noxious matter from a vessel or elsewhere.) The instruments used in cautery vary and several types are specified in Internal affections and elsewhere: the most common are rods of metal directly heated by fire-hence the injunction not to allow the instrument to become "white-hot"- or of wood, such as boxwood, heated by being dipped in hot oil. ${ }^{40}$ The use of vegetable matter, as in China and Japan—mykes "fungus"-is attested also, though it is not clear which plant was used. ${ }^{41}$

${ }^{37}$ Aph. 7. 87 [Littré, 4. 608].

${ }^{38}$ Galen, op. cit, note 19 above, Introductio seu medicus, 14. 782.

${ }^{39}$ Celsus 7. 7. 15.

${ }^{40}$ Int. 28 [Littré, 7. 242].
${ }^{41}$ Int. 19, 24, 25 [Littré, 7. 214, 228, 230]. Gynaecological works attest a secondary meaning mykes "suppuration"; this and the cognate verb mykoomai "suppurate" are perhaps allied with myxa "mucus" and the adjective myxodes "mucus-like", as in Mul. 1. 40 [Littré, 8. 96]. 


\section{Hippocratic Bodily “Channels” and Oriental Parallels}

Cautery and cutting were used to address many conditions, including eye troubles. The sites of surgery were chosen on the basis of supposed routes through the body, the aim being, precisely as in traditional Chinese medicine, to eliminate noxious stuff or to change the constitution or the consistency of body fluids coursing through the body; one such route carried the "marrow" or spinal fluid, believed to originate in the brain and allied also with semen. Treatment by phlebotomy and cautery have broad similarities to treatment by acupuncture and moxibustion. It has been suggested that phlebotomy and acupuncture are connected in origins; a parallel connection may be postulated between cauterization and moxibustion or acumoxa. Moxibustion preceded acupuncture in China just as cautery was more prevalent than cutting in early Greek medicine: primitive legends describe the making of different types of needles. ${ }^{42}$

\section{Ophthalmology}

In modern discussion of eye problems, topics are grouped together with reference to the part affected, known from dissection and the ophthalmoscope, but of course the ancient physician lacked this knowledge. Modern works, aimed to assist the hard-pressed family doctor to sort out ocular problems, suggest that the first distinction should be between gradual loss and sudden loss of sight; and that each of these sub-divisions should then be classified further on an anatomical basis, working posteriorly from lens to retina to choroid and optic nerves. ${ }^{43}$ The Hippocratic doctor, unable to examine the inside of the eye and unaware of its full complexity, uses a more crude yardstick, thinking in terms of ocular flux and tending to lump together superficially similar symptoms, not suspecting that these might have different origins. However, it was realized that the eyes are a good diagnostic indicator of health or disease; also that the eyes are affected in many apparently unrelated conditions (as is indeed the case with systemic diseases such as diabetes). Cataract—not in the classical period differentiated from glaucoma-was recognized as a degenerative disease; trachoma was endemic and other scrofular infections were prevalent.

The short treatise $O n$ sight gives instructions for surgical procedures to be followed in different ocular affections or diseases or, rather, to treat different sets of ocular symptoms. ${ }^{44}$ The procedures are: cautery of vessels $(1.1,2 ; 3)$ or of eyelid (4), cutting and/or scraping of eyelid (5), letting blood by phlebotomy or cupping $(3 ; 7 ; 9)$, cutting into the scalp (4. 2), trephination of the skull (8), purging the head and/or the body generally (1. 1,$2 ; 4 ; 7 ; 9)$, applying ointments and poultices $(6 ; 9)$. Our author shows little

\footnotetext{
${ }^{42}$ See S Kuriyama, The expressiveness of the body and the divergence of Greek and Chinese medicine, New York, Zone Books, 2002. For a fuller discussion of these views and of chronological questions, see E M Craik, 'Knife and fire: medical practice of east and west', in Proceedings of COE meeting held at Kyoto November, 2003, published as Globalization, Kyoto, Iwanami Shoten, 2004, pp. $227-43$.

${ }^{43}$ Textbooks - whether simple field guides such as Jonathan D Trobe and Richard E Hackel, Field
}

guide to the eyes, Philadelphia, Lippincott Williams \& Wilkins, 2002, or magisterial works of reference, such as David J Spalton, Roger A Hitchings and Paul A Hunter (eds), Atlas of clinical ophthalmology, Philadelphia, Elsevier Mosby, 2005-are arranged accordingly by lids, conjunctiva, iris, retina etc. ${ }^{44}$ Vid. Ac. [Littré, 9.152-60]. For a fuller discussion of ophthalmological questions touched on in this paper, see E M Craik, Two Hippocratic treatises: On sight and On anatomy, Leiden, Brill, 2006. 


\section{E M Craik}

awareness of the complex anatomy of the eye. Few technical terms are used. The phlebes "vessels" are important to his practices $(1.1 ; 3.1,3$ ter; 9. 1), but there is only one, imprecise, indication of particular vessels and their location (3. 1). The disconcerting absence of anatomical nomenclature is accompanied by a disconcerting lack of diagnostic comment. Retrospective diagnosis of Hippocratic cases is always hazardous, but in this case the conditions can be plausibly identified as follows: cataract and glaucoma (1), weeping sores and their complication ectropion (2), trachoma and its effects (4), palpebro-conjunctival cysts or lesions such as pterygion, papilloma or chalazion (5), "night vision" (7), recurrent seasonal allergy or conjunctivitis (9, cf. 6).

For eye troubles in other Hippocratic works, cautery of the vessels of the temples was regarded as the first recourse: in Places in man the vessels which "press on the eye, those which constantly beat and are situated between ear and brow", or in Diseases 2 these vessels comprehensively with six other vessels of the head. ${ }^{45}$ These other vessels are: two alongside the ears, two at the inner corners of the eyes, and two "behind the head on either side at the occiput". The reasons for these procedures are not stated, but on the basis of the theory which can be reconstructed from allusive references in Hippocratic texts and a full discussion in Celsus 6, it is evident that different types of flux are envisaged, and that, whereas cautery of the temporal vessels was the treatment for flux A, cautery of points behind the head was applied in case of flux B. This allows interpretation of a chapter in the treatise On sight, generally dismissed as out of place in the work. In a section dealing with general principles of cautery, the author indicates cautery of vessels "of the back" and "behind" ${ }^{46}$ As the adjective used is that commonly applied to the spinal fluid, the vessels loosely designated "of the back" may be more precisely designated as the vessels which run from head to neck to back, that is those through which the "marrow", or more properly "cerebral or spinal fluid" was believed to course from the brain to the eye or lower body (flux B). Other works confirm this interpretation. Cautery of the flesh of the neck is practised in Places in man to stop the progress of noxious matter "behind" and to divert it to the nose for expulsion. ${ }^{47}$ Similarly, cautery of the neck is prescribed in Internal affections for blockage in the "small vessels" from the brain. ${ }^{48}$ The passage of On sight belongs perfectly in the context of treatments for serious flux.

In the earliest extant Chinese medical texts, from the Mawangdui tombs dated to 168 BC, cautery is recommended for eye troubles, as in Greece of the classical period. ${ }^{49}$ The points selected for cutting and cautery by Hippocratic doctors attempting to arrest flux affecting the eye seem to correspond with the points addressed by modern oriental physicians treating eye complaints by acupuncture and moxibustion. In addition to points on the back of the head, both at crown and occiput, in the forehead, and in the eye area on the $d u$ channel, a trio of parallel channels is addressed: these are the $d u$ channel and

\footnotetext{
${ }^{45}$ Loc. Hom. 13 [Littré, 6. 298-302]; Morb. 2. 12

[Littré, 7. 18-22]; cf. 1 [Littré, 7. 8].

${ }^{46}$ Vid. Ac. 3 [Littré, 9. 154].

${ }^{47}$ Loc. Hom. 21 [Littré, 6. 312-14].

${ }^{48}$ Int. 13 [Littré, 7. 200].
} 


\section{Hippocratic Bodily “Channels” and Oriental Parallels}

two parallel yang channels, one on each side. ${ }^{50}$ In the particular case of eye diseases the treatment applied by Hippocratic doctors is similar to that with a long history in the east.

Of course, there is a ready explanation for similarities in treatment: doctors do not cut and burn for fun, but in the hope of a cure; and they do not advocate treatments which never work, or at least seem to work. Even today, the reason for the undoubted effectiveness of the practice of acumoxa is not understood: some suspect a psychological element. The treatment seems to stimulate the body to resist disease and to become stronger; but its workings, especially in relation to particular diseases, where it acts not merely as a palliative but actually as a remedy, are mysterious. It has been suggested that acupuncture raises the red corpuscle count and enhances blood circulation; that it stimulates the nervous system (perhaps through specific neurological reactions between parts treated and parts affected); that it provokes responses in the cerebral cortex which in turn react on the organs. What would be the effect of heating, burning, or even severing vessels in and around the head, especially those behind the ears and at the base of the skull? Ancient practitioners feared that incisions behind the ear-a regular treatment for a hip condition known as kedmata - would inhibit male fertility or potency, a further confirmation of the supposed connection between cerebral fluid and sperm. Relevant texts are Places in man, Epidemics 6, Airs, waters and places and Generation. ${ }^{51}$ Galen testifies to the continuing practice of radical phlebotomy in De methodo medendi and in De compositione medicamentorum secundum locos. ${ }^{52}$

\section{Conclusions}

Early Greek ideas about the routes of the phlebes have been much discussed, but always mapped against the system of veins and arteries, now known. It is natural that Harvey should be invoked in assessments of the accuracy of Hippocratic models of vascular anatomy. However, accuracy is not their main thrust and their theoretical or pragmatic slant renders a comparison with Chinese systems more apposite. And although the early development of Chinese "channels" is now being systematically studied, this is primarily in relation to later acumoxa practice. A thorough comparative representation of different Greek and different Chinese theories is a desideratum. Meantime, certain parallels are here revealed; the parallel between the Greek channel carrying myelos and the oriental $d u$ channel bearing the life force is particularly striking. Originally in China there was no elaborate system of acupuncture points (for example, twenty-eight points on the $d u$ channel) with measurements, any more than in Hippocratic practice. In sum, we see similar channels, with similar paths and similar contents, the focus of similar treatment for similar medical conditions.

This precise study suggests a possible broad conclusion: transmission of medical ideas between east and west in the centuries between 1000 and 500 BC. The debt of Homer to

\footnotetext{
${ }^{50}$ Cheng Xinnong (ed.), Chinese acupuncture and moxibustion, Beijing, Foreign Language Press, 1987, esp. pp. 231-3.

${ }^{51}$ Loc. Hom. 3 [Littré, 6. 282 L.]; Epid. 6. 5. 15 [Littré, 5. 320]; Aer. 22 [Littré, 2. 78]; Genit. 2
}

[Littré, 7. 472].

\footnotetext{
${ }^{52}$ Galen, op. cit., note 19 above, De methodo medendi, 10. 937; De compositione medicamentorum secundum locos, 12.701.
} 


\section{E M Craik}

the east is generally acknowledged. That there were routes from east to west-which might be covered by contiguous stages, rather than encompassed in a single journey-is evident from the presence of scraps of silk in Egypt and Europe long before our first written sources allude to it. ${ }^{53}$ This may already be too speculative for many readers. But a still bolder question may be posed in conclusion: is it a coincidence that Cos, home of Hippocrates and centre of Greek medicine, became a centre also of sericulture? ${ }^{54}$

The ground covered in this paper, though in one sense very wide (ranging over a vast chronological and geographical spectrum), is in another sense quite narrow (addressing only one aspect of vascular anatomy); similarly, the conclusions explicitly reached may be viewed as wide and positive (that real similarities exist between different belief systems) or as narrow and negative (that explanation of these similarities is problematical). An important further consideration, to be developed through examples in a later paper, is implicit. It is here argued that study of ancient anatomy has been unduly coloured by modern medical discoveries: in particular, it is difficult for the modern reader to forget Harvey. Similarly, it is apparent that interpretation of ancient physiology and pathology has paid insufficient attention to theories of flux and fixation of peccant matter: this too may be due to anachronistic attitudes, the focusing of attention on humoral theory and postulates of humoral imbalance, ideas which dominated western medicine from the renaissance to the nineteenth century. The western medical tradition claims Greek roots and has tended to read its own contemporary ideas and attitudes into the past, to the exclusion or downgrading of theories which do not "fit". But if, in certain respects, closer parallels can be found in an alien tradition, the modern view of ancient medicine is fundamentally challenged: Hippocratic doctors are to be viewed not as idealized progenitors but rather as in significant respects alien and indeed-to use the term commonly applied to Greek dramatic, social and religious institutions-“other".

\footnotetext{
${ }^{53}$ See, for example, Vadime Elisseeff (ed.), The silk roads: highways of culture and commerce, Paris, UNESCO, 1998.

${ }^{54}$ For a detailed examination of this question, see Craik, op. cit., note 42 above; for a short summary, see
}

E M Craik, 'The lasting significance of Hippocratic medicine', in A Chaniotis and C Kuhn (eds), Historizing classics: continuities, contrasts, controversies, Stuttgart, Franz Steiner, 2008, section 6. 